\title{
Quantification of pregnant mothers' intention towards infant and young child feeding: a clinic based study in rural West Bengal, India
}

APARAJITA DASGUPTA, SWANYA P. MAHARANA*, BOBBY PAUL and SHOBHIT GARG

Department of Preventive \& Social Medicine, All India Institute of Hygiene and Public Health, Kolkata, West Bengal, India

\begin{abstract}
Background: Malnutrition has become the biggest contributor to child mortality in recent years accounting for about half of all child deaths. The most important way to prevent this dismal status is by promoting optimal breastfeeding and infant feeding to all the babies. Intentions have been considered the strongest factor to influence one's behaviour.

Objectives: To assess the intention of pregnant women towards infants and young child feeding (IYCF) and the factors associated with it.

Methods: A clinic based cross-sectional study was conducted in an antenatal unit of a primary health centre in Singur block of Hooghly district in West Bengal, India. A total of 137 pregnant women were interviewed using a questionnaire to assess their intention towards IYCF after taking their written informed consent. Descriptive characteristics, univariate and hierarchical logistic regression were used to analyse the data.

Results: All the women (137) intended to breastfeed their future offspring. Only 88 (64.2\%) intended to feed colostrum whereas 112 (81.75\%) had intention to breastfeed exclusively. The majority (82.5\%1) answered correctly when asked about the timing of initiation of complementary feeding. Overall $83(60.58 \%)$ had favourable intention towards IYCF. The significant covariates of favourable intentions towards IYCF were higher socio-economic status [OR ( $\mathrm{Cl})$; 4.4 (1.7-11.6)], working mothers [OR ( $\mathrm{Cl}) ; 4.3$ (1.03-18.3)] and multigravida [OR(CI);9.7(2.2-42.7)].

Conclusion: Focusing on developing favourable intention towards IYCF during every antenatal visit of every pregnant woman and counselling will be a cost-effective intervention to ensure excellent growth and development among children and it is a well-established that healthy children will give forth to a healthy nation.
\end{abstract}

Keywords: infant, child, breastfeeding, intention, pregnant women, India

\section{Introduction}

All children have a right to survive, thrive and fulfil their potential - to the benefit of a better world (UNICEF, 2017). Infants and young children need the right foods at the right time to grow and develop to their full potential. But, sadly 16,000 children under five years old die each day, half of whom do not live to become an infant (WHO/UNICEF/World Bank, 2015). The one major cause to blame is malnutrition. Malnutrition has become the biggest contributor to child mortality in recent years accounting for about half of all child deaths, most of them during infancy (WHO, 2016). India, the second largest country in the world, accounts for $38 \%$ of moderately or severely malnourished children worldwide (IAP, 2015). Despite immense progress in numerous sectors especially health and education and a fast growing economy, it is unfortunate that India still lags behind the Millennium Development Goals (MDG) of under-five mortality and infant mortality rates (GOI, 2014). Presently, 36 percent of under five children in India are reported to be underweight and 38 percent are stunted with $50 \%$ under-five mortality (NFHS, 2016).

The most important cause of malnutrition setting in early in life is the faulty and suboptimal IYCF practices. In India, in a survey conducted in 2015, 54.9\% of infants under 6 months of age were exclusively breastfed whereas after 6 months the percentage of children receiving solid or semi-solid food and breastmilk declined to $42.7 \%$ (NFHS-4, 2015-

\footnotetext{
*Correspondence E-mail: swanyamaharana@gmail.com
} 
16). Similar scenario in various states including rural West Bengal where $47.2 \%$ children under age 3 years were breastfed within one hour of birth, 49.6\% children under age 6 months were exclusively breastfed and $54.3 \%$ children aged $6-8$ months received solid or semi-solid food and breastmilk (NFHS-4, 2015-16).

The most important way to prevent this dismal status is by promoting optimal IYCF to all the babies. Optimal infant and young child feeding practices rank among the most effective interventions to improve child health (WHO, 2009). It has been proved that the first 1000 days of life i.e., the 270 days in-utero and the first two years after birth is the critical window period for nutritional interventions (Black et al., 2008: Black et al., 2013 ). Maximum neurophysiological development occurs during this period and therefore, malnutrition during this critical period can lead to suboptimal development of the child (WHO, 2001; UNICEF, 2011). Breastfeeding is a miraculous, natural, perfect food for the new-born (UNICEF \& WHO, 2015). Breastfeeding is regarded as the most cost-effective public health measure that significantly impacts infant morbidity and mortality in developing countries like India. (Leshi et al., 2016).

Optimal breastfeeding of infants under two years of age has the greatest potential impact on child survival of all preventive interventions, with the potential to prevent over 800,000 deaths ( 13 per cent of all deaths) in children under five in the developing world (Black et al., 2013). While breastfeeding provides optimal nutrition to the child, improvements in complementary feeding can substantially reduce stunting and related burden of disease. Studies have shown that the most vulnerable time for the infant is during introduction of complementary feeding as not only the feeding requirements change but they are also exposed to more number of infections (WHO, 2001; Rao et al., 2010).

The key person who stands between the life and death of a child is, undoubtedly - the mother. If the mothers are ready, willing to feed their babies as required, a vast majority of child deaths and diseases can be prevented. For mothers to provide optimum IYCF, they should have a strong intention to do so. According to the theories of planned behaviour and reasoned action, the stronger the intention to engage in a behaviour, the more likely should be its performance (Ajzen, 1991). Various studies have inferred that intention as the immediate precursor of voluntary action. Behavioural intention mediates all other factors influencing behaviour (Baisch et al., 1989; Manstead et al., 1983; Kessler et al., 1995). In the context of IYCF, studies have shown that the practice of breastfeeding may be influenced by many factors but it is most strongly related to the women's prenatal intention (Bonuck et al., 2005; Bai et al., 2010).

Assessment of intention of a pregnant woman is a less studied but key, modifiable factor which plays a pivotal role in shaping the behaviour of the future mother. An expecting mother is on the verge of stepping into motherhood. During this phase, she is naturally the most susceptible to be motivated for the well-being of her future child. Therefore, to promote optimal IYCF practices since the first day of birth, it is important to focus research to assess and strengthen their intention towards IYCF. India is a resourcepoor developing country with a huge burden of under-five mortality. It is imperative that newer cost-effective strategies like strengthening intention of women, be devised to promote optimal IYCF, especially among rural women. There is a dearth of research on intention of women in India, that too in rural areas. With this backdrop, the present study was done to assess the intention of the expecting mothers towards IYCF and to determine its predictors.

\section{Materials and Methods} Study setting and sampling 
This was a clinic based observational study done in a cross-sectional design from April to June 2016. It was done in a Primary Health Centre (PHC) under Rural Health Unit and Training Centre, Singur (RHUTC) which is the rural field practice area of All India Institute of Hygiene and Public Health(AllH\&PH), Kolkata, West Bengal District in India. RHUTC, Singur serves 64 villages with approximate 100,000 populations through two Union Primary Health Centre (UPHC) and 4 sub-centres.

All expecting mothers who came to the antenatal clinic during the study period were approached for the study and whoever gave the written informed consent were considered in the study.

\section{Data collection}

Data was collected using a structured pre-tested pre-designed schedule which had 3 parts: (i) Socio-demographic characteristics; (ii) Obstetric history; and (iii) An instrument to assess Intention towards IYCF. In socio demographic part age, caste, religion, education, occupation, husband's occupation, type of family, socio-economic status (SES) (Prasad, 1970; Vasudevan et al., 2016; Sharma, 2016), current place of stay and age at marriage were asked to each participant. For obstetrical history each participant was asked about parity, history of previous abortion and no. of living children. Eighteen questions were asked to each woman regarding their intention towards feeding their expectant child. The questions focused on their intention to feed immediately after birth, exclusive breastfeeding, complementary feeding, feeding during sickness (infectious diseases are very prevalent in rural community) and on continuation of breastfeeding. Each question was scored "one" for favourable response except two questions on intention to exclusive breastfeed which were scored "one" only when both were answered favourably. Every unfavourable response was scored as "zero". Responses which were optimal for newborn and infant health were considered favourable. For example, initiation of breastfeeding with one hour of delivery was considered favourable. Any response other than this was considered as "unfavourable". After adding all the responses, total score was calculated for each woman. Women who had scored more than $50 \%$ of the attainable score were considered as having favourable intention towards IYCF. As maximum attainable score is 17 so women with score more than equal to "nine" were considered as having favourable intention towards IYCF.

Content validity Index (CVI) was used to assess the content validity. Cut off of 0.7 was considered optimum for considering the respective item. Cronbach's alpha was investigated on a sample of 30 expecting mothers after pre-testing which was found to be 0.716 showing an acceptable internal consistency. Mother Child Protection (MCP) card was reviewed for no. of antenatal visits and for noting last menstrual period (LMP) to calculate gestational age.

\section{Data analysis}

All analyses were conducted with the SPSS software version 16.0 (Statistical Package for the Social Sciences Inc., Chicago, IL, USA). Initially all independent variables were investigated for outcome variable i.e. favourable and unfavourable intention with univariate binary logistic regression. All the predictor variables that came significant at $5 \%$ level in bivariate analysis were further investigated with outcome variable with 3 step hierarchical logistic regression with level of significance at $5 \%$.

In the first step individual predictors like age and working status were added, in step 2 family related factors (type of family and SES) were added and in the final steps obstetric characteristics were further added. Multicollinearity among all the independent variables was tested by the level of Variance Inflation Factor before entering into the regression model. Model fit was assessed using Hosmer-Lemeshow statistics. 


\section{Ethical considerations}

The study was conducted after seeking ethical approval from the Institutional Ethics Committee of All India Institute of Hygiene and Public Health (AIIH\&PH).

\section{Results}

The mean age of the study participants was $22.98 \pm 3.82$ years. Mean years of schooling was $10.08 \pm 2.9$ years. Among 137 pregnant women, 120 (87.6\%) belonged to joint family and 116 (84.7\%) were home-makers. Among 137, 88 (64.2\%) belonged to general caste and 115 (83.9\%) were Hindus. Mean gestational age was $22.1 \pm 8.8$ weeks. 96 (70.1\%) had less than four antenatal care visits, $32(25.5 \%)$ had at least one living child, $24(17.5 \%)$ had history of abortion while 87 (63.5\%) were primigravida. (Table 1 ).

Table 1: Distribution of study participants according to socio-demographic and obstetric characteristics $(\mathrm{N}=137)$

\begin{tabular}{|c|c|c|}
\hline Variable & Attribute & Number (percentage) \\
\hline \multirow[t]{2}{*}{ Occupation } & Work for pay & $21(15.3)$ \\
\hline & Home maker & $116(84.7)$ \\
\hline Age at Marriage & $<18$ years & $27(19.7)$ \\
\hline \multirow[t]{2}{*}{ Current Stay } & Without mother & $105(76.6)$ \\
\hline & With mother & $22(23.4)$ \\
\hline \multirow[t]{7}{*}{ Husband's Occupation } & Unskilled labour ${ }^{a}$ & $11(8)$ \\
\hline & Semi-skilled labour ${ }^{\text {b }}$ & $56(40.9)$ \\
\hline & Skilled labour ${ }^{c}$ & $19(13.9)$ \\
\hline & Clerk & $14(10.2)$ \\
\hline & Teacher & $6(4.4)$ \\
\hline & Farmer/Cultivator & $13(9.5)$ \\
\hline & Business & $18(13.1)$ \\
\hline \multirow[t]{2}{*}{ Per Capita Income (PCI) (INR) } & Mean (SD) & $1883.43(2131.80)$ \\
\hline & Median (IQR) & $1250.00(750.0-2000.0)$ \\
\hline \multirow[t]{5}{*}{ Socioeconomic status } & Class I $(\geq 6261)^{\$}$ & $4(2.9)$ \\
\hline & Class II (3099 - 6260)\$ & $15(10.9)$ \\
\hline & Class III $(1835-3098)^{\$}$ & $27(19.7)$ \\
\hline & Class IV $(949-1834)^{5}$ & $49(35.8)$ \\
\hline & Class V $(<948)^{\xi}$ & $42(30.7)$ \\
\hline Ante Natal Care Visits & $<4$ & $96(70.1)$ \\
\hline \multirow[t]{2}{*}{ Gravidity } & Multigravida & $50(36.5)$ \\
\hline & Primigravida & $87(63.5)$ \\
\hline Living children & Yes & $35(25 \cdot 5)$ \\
\hline Previous abortion & Yes & $24(17.5)$ \\
\hline
\end{tabular}

Key: INR = Indian National Rupee; SD= Standard Deviation; IQR= Inter Quartile Range; $\$=$ Figure in bracket is $\mathrm{PCl}$ for that category; $\mathrm{a}=$ sweeper, factory workers, vegetable and fruit vendor; $\mathrm{b}=$ auto driver, painter, carpenter, tailor; c= electrician, jewellery workers

All (100\%) the pregnant women intended to breastfeed their future offspring. Eighty-eight (64.2\%) of them intended to feed their offspring with colostrum. $112(81.75 \%)$ had intention to breastfeed their child exclusively. But nearly $70 \%$ of women did not intend to continue breastfeeding when they would suffer from diseases. (Table 2)

Table 2: Intention of study participants towards IYCF $(\mathrm{N}=137)$

\begin{tabular}{llll}
\hline SNO & Question & $\begin{array}{l}\text { Favourable } \\
\text { response }\end{array}$ & $\begin{array}{l}\text { Favourable } \\
\mathrm{N}(\%)\end{array}$ \\
\hline
\end{tabular}


1. What is the first food that you intend to offer to the Breast-milk baby after birth?

2. Do you intend to breastfeed your baby?

3. When do you plan to breastfeed your baby after birth?

4. Do you intend to feed colostrum to your baby?

5 A Till what age of the baby do you intend to give only breast milk?

5 B After birth, do you intend to give any other feed along with breast milk to your baby?

6. Do you intend to continue breastfeeding when your Yes baby is sick?

7. Do you intend to continue breastfeeding if you suffer Yes from fever

8. Do you intend to continue breastfeeding if you suffer Yes from malaria

9. Do you intend to continue breastfeeding if you suffer Yes from dengue?

10. Do you intend to continue breastfeeding if you suffer No from breast infections?

11. Do you intend to continue breastfeeding if you suffer from tuberculosis?

Do you intend to continue breastfeeding if you suffer from diarrhoea?

13. How do you intend to feed the baby in your absence?

14. Do you intend to use bottle to feed your baby?

15. At what age of the baby will you start complementary feeding to your baby?

With what food do you intend to start complementary

16 feeding?

Till what age of the baby do you intend to continue

17. breastfeeding your baby?
Yes

Within one hour

Yes

Six months

No

Yes

No

Yes, treatment

Yes

Expressed Breast Milk

No

After completing six months

Locally available

semi-solid food

Two years and 94(68.6) above
$134(97.8)$

137(100)

101(73.7)

88(64.2)

123(89.78)

112(91)

112(81.8)

42(30.7)

$36(26.3)$

34(24.8)

133(97.1)

with $33(24.1)$

43(31.4)

39(28.5)

$111(81)$

$113(82.5)$

$122(89.1)$

Locally available semi-solid food - 'khichdi'-a mix of rice, pulses, vegetables and nuts boiled together; mashed banana, mashed potato; semolina porridge and others. The maximum score attained was 17 and minimum was 4. The mean (SD) score was 10.8 (3.3). Eighty-three (60.58\%) pregnant women had favourable intention towards IYCF (Figure 1).

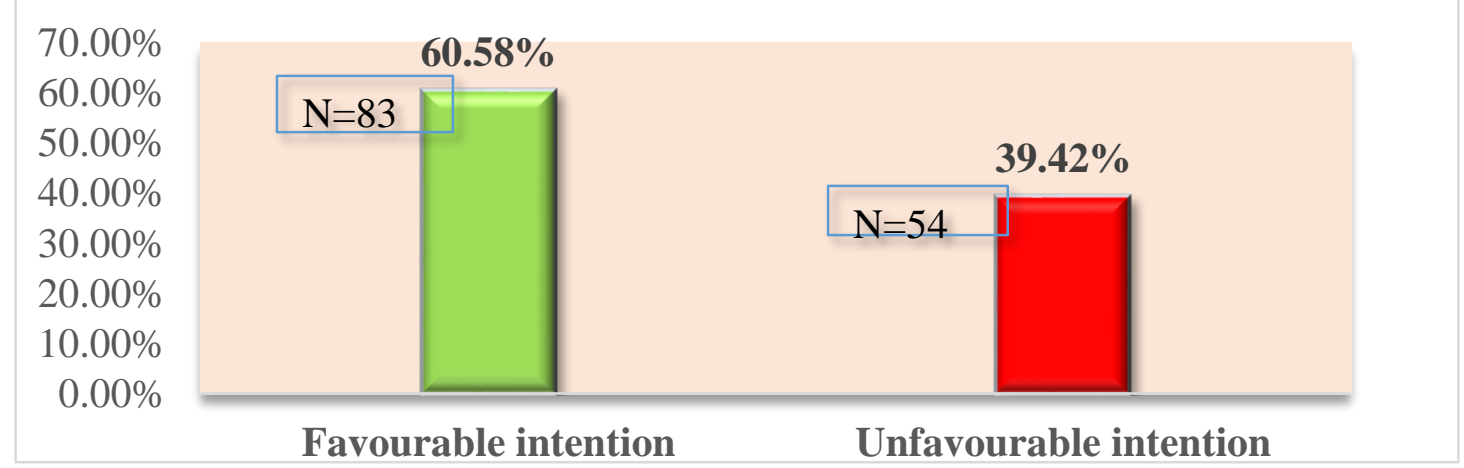

Figure 1: Distribution of pregnant women according to their intention towards IYCF 
Among the women who did not have the intention to feed their child with colostrum, $39(79.6 \%)$ had no reason for such intention while $3(6.12 \%)$ described colostrum to bed problematic and not good for health. (Table 3 ).

Table 3: Predominant reasons believed by women who did not intend to feed colostrum $(\mathrm{N}=49)$

\begin{tabular}{ll}
\hline Reasons for No Colostrum feeding & $\mathbf{N}(\%)$ \\
\hline Don't know & $39(79.6)$ \\
Not good for Health & $3(6.12)$ \\
Problematic & $3(6.12)$ \\
Thick, difficult to digest & $4(8.16)$ \\
Total & $49(100)$ \\
\hline
\end{tabular}

With one-unit increase in age of the woman it was found that odds of favourable intention was 1.2. Women who were working for pay $(\mathrm{OR}=4.7)$, belonged to nuclear families ( $O R=5.7)$, higher socio-economic status ( $O R=3.4)$, had abortion history ( $O R=9.4)$, were multigravidas $(\mathrm{OR}=11.6)$ and had at least one living child $(\mathrm{OR}=7.4)$ had higher odds of favourable intention towards IYCF. (Table 4).

Table 4: Predictors of favourable intention towards IYCF: Univariate logistic regression ( $\mathrm{N}=137)$

\begin{tabular}{|c|c|c|}
\hline Variable & Favourable Intention & $\mathrm{OR}(\mathrm{Cl})$ \\
\hline & \multicolumn{2}{|l|}{$\mathbf{N}(\%)$} \\
\hline Age & & $1.2(1.1-1.3)$ \\
\hline Education & & $0.95(0.8-1.1)$ \\
\hline Occupation (Work for pay) $(n=21)$ & $18(85.7)$ & $4.7(1.3-16.9)$ \\
\hline Age at Marriage $(<18$ years $)(n=27)$ & $15(55.6)$ & $0.8(0.3-1.8)$ \\
\hline Caste $\quad(O B C / S C / S T)(n=49)$ & $29(59.2)$ & $0.92(0.4-1.9)$ \\
\hline Religion (Hindu) $(n=115)$ & $73(63.5)$ & $2.1(0.83-5.2)$ \\
\hline Family Type (Nuclear) $(n=17)$ & $15(88.2)$ & $5.7(1.3-26.2)$ \\
\hline Current Stay (Without In-laws) $(n=32)$ & $23(71.9)$ & $2(0.8-4 \cdot 5)$ \\
\hline \multicolumn{3}{|l|}{ Husband Occupation } \\
\hline - Unskilled $(\mathrm{n}=11)$ & $4(36.4)$ & $0.32(0.09-1.2)$ \\
\hline - Semi-skilled $(n=56)$ & $34(60.7)$ & $0.86(0.4-1.8)$ \\
\hline Socioeconomic status Class I, II, III $(n=46)$ & $36(78.3)$ & $3.4(1.5-7.6)$ \\
\hline Abortion History (Yes) $(n=24)$ & $22(91.7)$ & $9.4(2.7-32.9)$ \\
\hline ANC Visits $(<4)(n=96)$ & $63(65.6)$ & $2(1.1-3.7)$ \\
\hline Gestational Age & & $1(0.96-1.04)$ \\
\hline Gravida (Multigravida) $(\mathrm{n}=50)$ & $45(90)$ & $11.6(5-27.2)$ \\
\hline Living children (Yes) $(\mathrm{n}=35)$ & $31(88.6)$ & $7.4(2.9-18.9)$ \\
\hline
\end{tabular}

The hierarchical multiple logistic regression revealed that at Step one individual factors (age and working status) accounted for $15.4 \%$ of the variation in intention towards IYCF. Introducing family related factors (family type and socio-economic status) explained an additional $8.9 \%$ of variation in intention towards IYCF with higher socio-economic status was found to have significant odds of 3.4. Further addition of obstetrical factors explained an additional $17.7 \%$ of variation in intention towards IYCF with significant odds for individual of higher socio-economic status ( $\mathrm{OR}=4.4)$, who worked for pay $(\mathrm{OR}=4.3)$ and for individual with living children $(O R=9.27)$. At all three steps model was fit as shown by the nonsignificant Hosmer-Lemeshow statistic. At all three levels model correctly predicted $69 \%-$ $77 \%$ of the dependent variable (Table 5). 
Table 5: Predictors of favourable intention towards IYCF - Hierarchical logistic regression $(\mathrm{N}=137)$

\begin{tabular}{|c|c|c|c|}
\hline Variables & $\begin{array}{l}\text { Step } 1 \\
\text { OR }[\mathrm{Cl}]\end{array}$ & $\begin{array}{l}\text { Step } 2 \\
\text { OR }[\mathrm{CI}]\end{array}$ & $\begin{array}{l}\text { Step } 3 \\
\text { OR }[\mathrm{Cl}]\end{array}$ \\
\hline Age & $\begin{array}{l}1.2 \\
(1.05-1.3)\end{array}$ & $\begin{array}{l}1.2 \\
(1.04-1.3)\end{array}$ & $\begin{array}{l}1.05 \\
(0.9-1.2)\end{array}$ \\
\hline Work for Pay $(n=21)$ & $\begin{array}{l}4 \cdot 3 \\
(1.2-15 \cdot 8)\end{array}$ & $\begin{array}{l}4.4 \\
(1.1-17)\end{array}$ & $\begin{array}{l}4.3 \\
(1.03-18.3)\end{array}$ \\
\hline Nuclear Family $(n=17)$ & & $\begin{array}{l}2.3 \\
(0.4-12.7)\end{array}$ & $\begin{array}{l}1.1 \\
(0.2-7 \cdot 3)\end{array}$ \\
\hline $\begin{array}{l}\text { Class I, II, III Socio } \\
\text { economic } \\
(n=46)\end{array}$ & & $\begin{array}{l}3.4 \\
(1.4-8.3)\end{array}$ & $\begin{array}{l}4.4 \\
(1.7-11.6)\end{array}$ \\
\hline $\begin{array}{l}\text { No of ANC visit } \leq 3 \\
(n=96)\end{array}$ & & & $\begin{array}{l}1.4 \\
(0.5-3.4)\end{array}$ \\
\hline $\begin{array}{l}\text { Previous Abortion } \\
\text { History }(n=24)\end{array}$ & & & $\begin{array}{l}1.5 \\
(0.2-11)\end{array}$ \\
\hline $\begin{array}{l}\text { Living children present } \\
(\mathrm{n}=35)\end{array}$ & & & $\begin{array}{l}\text { Not included due to } \\
\text { interaction }\end{array}$ \\
\hline Multigravida $\quad(n=50)$ & & & $\begin{array}{l}9.7 \\
(2.2-42.7)\end{array}$ \\
\hline Nagelkarke $\mathrm{R}^{2}$ & 0.154 & 0.243 & 0.42 \\
\hline
\end{tabular}

\section{Discussion}

Slightly lower that two thirds of all women interviewed were found to have favourable intention towards IYCF, while the majority intended exclusive breastfeeding. In this study all women intended to breastfeed their expectant child as noted in a similar study in rural Odisha (Behera \& Pillai, 2016) but this finding differs from that of Nigeria (Leshi et al.,2016) where $90.6 \%$ women intended to breastfeed. In a study in the United States (Sipsma et al., 2013) $73 \%$ pregnant women reported intention to breastfeed, $77.2 \%$ in Syria $76.2 \%$ of mothers (Akour et al.,2010) and 60\% women in Philadelphia (Hundalani et al., 2013) intended to breastfeed, respectively. This remarkable difference across various countries may be due to cultural differences and varying popular beliefs and practices.

In rural Odisha (Behera \& Pillai, 2016), two thirds of women intended to exclusively breastfeed which differs from the finding in our study. This difference may be due to lack of adequate knowledge of benefits of exclusive breastfeeding and lack of proper antenatal counselling and care in rural Odisha which is an economically backward state. Leshi et al. (2016) found only $60 \%$ women of Nigeria intended to exclusively breastfeed. This further emphasizes the role of antenatal counselling and care in shaping a women's intention. Three-quarters expecting women intended to early initiate breastfeeding in the present. This proportion is lower than that reported in Odisha (Behera \& Pillai, 2016) but higher than in a study in Nigeria (Leshi et al., 2016). A striking result was found that nearly 7 out of 10 of the women did not intend to breastfeed their child when they suffered from various diseases (malaria, diarrhoea) though the diseases would not be transmitted through breastmilk. This refusal could be key to inadequate IYCF as such infections are frequent in rural India.

Overall this cross-sectional study found that women of higher socio-economic status, those who were working and those who were multigravida had the higher odds of having favourable intention towards IYCF. The women of higher socio-economic status may be more aware about child care and the benefits of breastfeeding as they visit doctors more often. The women who work for pay usually have more opportunities to gather knowledge and since they are working they might be more cautious about child care, hence with 
favourable intention. Women who had a previous child are more experienced in child care. They knew better about the benefits of optimum breastfeeding and adequate infant feeding. We also found that those expecting mothers who already had living children had higher intention than those who had none as multiparous women are more experienced in taking care of their children. This finding is similar to the finding of a comparative study done in among Syrian and Jordanian women (Akour et al., 2010).

This study has some limitations. Firstly, the sample size was small. Secondly, many factors known to have impact on intention such as mental status of the mother, husband's intentions were not investigated in the present study (Borra et al., 2015). As it is a clinic based study, the findings cannot be generalized.

To conclude, women of higher socio-economic status, working women and those who already lost a child or have living children have greater intention to adequately feed their future offspring. If such antenatal women are called to counsel the other antenatal mothers in the clinic as a group counselling, the desired behaviour of timely, adequate infant feeding can be achieved. Every woman during her antenatal check-up should be screened for low socio-economic status, home-maker or primigravida and should be counselled to develop favourable intention towards IYCF. This will be a cost-effective intervention to improve the infant feeding practices. A multi centric study with more sample size and broader conceptual framework is warranted for further addition in the causal pathway for poor intention towards IYCF so that the health policy makers could incorporate better policies for expecting mothers to improve infant feeding.

\section{References}

Ajzen, I. (1991). The theory of planned behavior. Organizational Behavior and Human Decision Processes 50: 179-211.

Akour, N.A., Khassawneh, M.Y., Khader, Y.S., Ababneh, A.A. \& Haddad, A.M. (2010) Factors affecting intention to breastfeed among Syrian and Jordanian mothers: a comparative cross-sectional study. International Breastfeeding Journal 5: 6.

Bai, Y., Middlestadt, S.E., Peng, C.-Y.J. \& Fly, A.D. (2010) Predictors of continuation of exclusive breastfeeding for the first six months of life. Journal of Human Lactation 26:26-34.

Behera, D. \& Pillai, A.K. (2016) Intention toward optimal breastfeeding among expecting mothers in Angul district of Odisha, India. Indian Journal of Public Health 60: 81-5.

Black, R.E., Allen, L.H., Bhutta, Z.A., Caulfield, L.E., de Onis, M., Ezzati, M., Mathers, C., Rivera, J., \& Maternal and Child Undernutrition Study Group. (2008) Maternal and child undernutrition: Global and regional exposures and health consequences. Lancet 371: 243-60.

Black, R.E., Victora, C.G., Walker, S.P., Bhutta, Z.A., Christian, P., Onis, M., Ezzati, M., Grantham-McGregor, S., Katz, J., Martorell, R., Uauy, R., \& the Maternal and Child Nutrition Study Group. (2013) Maternal and Child Undernutrition and Overweight in Low-Income and Middle-Income Countries. Lancet 382: 427-451.

Bonuck, K.A., Freeman, K. \& Trombley, M. (2005) Country of origin and race/ethnicity: Impact on breastfeeding intentions. Journal of Human Lactation 21:320-326.

Borra, C., lacovou, M. \& Sevilla, A. (2015) New evidence on breastfeeding and postpartum depression: the importance of understanding women's intentions. Maternal and Child Health Journal 19: 897-907.

GOI (2014) Millennium Development Goals India Country Report. Ministry of Statistics and Programme Implementation. Government of India, New Delhi http://www.mospi.gov.in/ Accessed on 29.8.16. 
Hundalani, S.G., Irigoyen, M., Braitman, L.E., Matam, R. \& Mandakovic, F.S. (2013) Breastfeeding among innercity women: from intention before delivery to breast feeding at hospital discharge. Breastfeeding Medicine 8: 6872.

IAP (2015) Infant and Young Child Feeding \& Human Milk Banking Guidelines 2: National Guidelines on Infant and Young Child Feeding. Indian Academy of Pediatrics. http://www.iapindia.org/files/HBA2015.pdf Accessed on 29.8.16

Leshi, O., Samuel, F.O. \& Ajakaye, M.O. (2016) Breastfeeding Knowledge, Attitude and Intention among Female Young Adults in Ibadan, Nigeria. Open Journal of Nursing 6: 11-23.

Manstead, A.S.R., Proffitt, C. $\quad$ \& Smart, J.L. $\quad$ (1983) Predicting and understanding mothers' infant feeding intentions and behaviour: Testing the theory of Reasoned Action. Journal of Personality and Social Psychology 44: 657-671.

NFHS (2016) India Factsheet. International Institute for Population Sciences (IIPS) and Macro International, Mumbai. http://rchiips.org/nfhs/pdf/NFHS4/India.pdf

Prasad, BG (1970). Changes proposed in the social classification of Indian families. Journal of Indian Medical Association 55:198-9.

Rao, S., Swathi, P.M., Unnikrishnan, B. \& Hegde, A. (2011) Study of complementary feeding practices among mothers of children aged six months to two years - A study from coastal south India. Australasian Medical Journal 4:252-257.

Sharma, R (2016). Online Interactive Calculator for Real-time Update of the Prasad's Social Classification. http://www.prasadscaleupdate.weebly.com Accessed on 29.8.16.

Sipsma, H.L., Divney, A.A., Magriples, U., Hansen, N., Gordon, D. \& Kershaw, T. (2013) Breastfeeding Intentions Among Pregnant Adolescents and Young Adults and their partners. Breastfeeding Medicine 8: 374-380.

UNICEF (2011) Infant and Young Child Feeding: Programming Guide 2-5 https://www.unicef.org/nutrition/files/Final_IYCF_programming_guide_2011.pdf.

UNICEF \& WHO (2015) Breastfeeding Advocacy Initiative: For the best start in life http://www.who.int/nutrition/publications/infantfeeding/breastfeeding_advocacy initiative_overview.pdf?ua=1.

UNICEF (2017) Improving Breastfeeding, Complementary Foods and Feeding Practices https://www.unicef.org/nutrition/index_breastfeeding.html.

Vasudevan, J., Mishra, A.K. \& Singh, Z. (2016) An update on B. G. Prasad's socioeconomic scale. International Journal of Research in Medical Sciences 4:4183-4186

WHO (2001) Complementary Feeding - Report of the Global Consultation Summary of Guiding Principles.

Geneva. www.who.int/entity/nutrition/publications/infantfeeding/Complementary_Feedin g.pdf.

WHO/UNICEF (2003) Global Strategy for Infant and Young Child Feeding. http://www.who.int/nutrition/publications/infantfeeding/9241562218/en/index.ht $\mathrm{ml}$ Accessed on 27.8.16

WHO (2009) Infant and young child feeding Model Chapter for Textbooks for Medical Students and Health Pllied Professionals. http://apps.who.int/iris/bitstream/10665/44117/1/9789241597494_eng.pdf?ua=1

WHO (2016) Children: Reducing Mortality. World Health Organisation, http://www.who.int/mediacentre/factsheets/fs178/en Accessed 29.8.16.

WHO/UNICEF/World Bank (2015) Child Mortality Rates Plunge by More Than Half Since 1990 but Global MDG Target Missed by Wide Margin. Joint news release http://www.who.int/mediacentre/news/releases/2015/child-mortality-report/en/. 